Contr. Mineral. and Petrol. 37, 90 (1972)

(C) by Springer-Verlag 1972

\title{
Erratum
}

\section{Structural Variations in Anorthites}

W. F. Müller, G. Thomas, and H. R. Wenk

Contr. Mineral. and Petrol. 34, 304-314 (1972)

Received June 28, 1972

P. 306, Table 1: The Greek letters $\Theta$ and $\Phi$ for the Eulerian angles are interchanged. The headings should be in sequence $\Phi, \Psi, \Theta$.

Prof. H. R. Wenk

Department of Geology and Geophysies

University of California

Berkeley, California 94720, U. S. A. 